\title{
Assessing the Performance of a Sludge Line in a Wastewater Treatment Plant
}

\author{
Mohamed H. Hegazy, Mohamed A. Tahalawy and Shady. M. Ahmed
}

\begin{abstract}
Dealing with sludge resulted from wastewater treatment process is one of the important issue in any treatment plant. The main objective for the digestion of sludge is to reduce its weight and volume in order to minimize the cost of sludge disposal. In our research we monitor the sludge line in a municipal wastewater treatment plant in Cairo, Egypt. We were focused on observing the efficiency of sludge digestion through all the stages of the sludge line. It is observed that the average concentration of suspended solids ranged between $8.5 \mathrm{~g} / \mathrm{l}$ at the first stage of the sludge line and $37 \mathrm{~g} / \mathrm{l}$ at the last sludge digestion stage with average $42.8 \%$ of VDS. Based $\mathrm{n}$ the results it shows that the sludge line at Gabal El-Asfar wastewater treatment plant GAWWTP is operating with acceptable efficiency, but it will need a future modification if the treatment plant flow increase to its full capacity. Also based on the results we found the the concentration of chromium $\mathrm{Cr}$ in sludge are very close to the permissible limit.
\end{abstract}

Keywords - Wastewater treatment, Sludge, DAF, Sludge thickening, Digestion of sludge, Dewatering.

\section{INTRODUCTION}

$\mathrm{W}$ astewater treatment plant produce a large volume of sludge. This sludge should be subjected to a digestion process before its disposal. Primary sludge is very putrescible, foul smelling, grey, and 60-70\% of it consists of volatile solids. Secondary sludge is brown and odorless and is mostly a microbial mass that $70-80 \%$ of its volume consists of volatile organic solids [1]. For the time being, technologies for achieving sludge reduction can be divided into two types, (a) reducing sludge production in wastewater treatment line, and (b) achieving sludge reduction in sludge treatment line [2].

Sewage sludge contains significant amounts of resources, such as nutrients and organic matter. At the same time, the organic contaminants OC found in sewage sludge are of growing concern [3]. Advanced wastewater treatment technologies have resulted in a higher quality of the effluent but some of them have also increased the amount of sludge generated in the process. At the same time, the traditional disposal routes of sludge, such as dumping in the sea and landfill disposal, are no longer possible due to tightening environmental regulations. Moreover, agricultural use faces increasing opposition because of the potential harmful effects of organic contaminants (OC). As a result, incineration of

Mohamed H. Hegazy, Mohamed A. Tahalawy and Shady. M. Ahmed are with the Department of Civil Engineering and Construction, British University in Egypt (BUE) Shorouk City, Cairo, Egypt sludge has become increasingly popular in the European countries [4].

In the sludge treatment line, sludge is subject to thickening, stabilization, dewatering and final disposal. Anaerobic digestion is the most commonly used sludge stabilization method, which is used to reduce the mass of sludge [5]. The sludge line at Gabal El-Asfar Treatment plant mainly composed of primary and secondary gravity thickeners, dissolved air floatation DAF unit, Sludge digesters, and dewatering facilities. The main purpose for exist a dissolved air flotation (DAF) tank in the treatment plant is to improve the stage of waste sludge thickening. This done by reducing the volume of sludge before it enters the digestion stage. A smaller volume of sludge will result in a higher efficiency of sludge digestion and a lower disposal cost for the digested sludge. Under the effect of air bubbles flowing upwards, the sludge solids are trapped by the bubbles and carried to the surface and skimmed out of the DAF tank by a skimmer. The thickened sludge is pumped to the sludge digesters for digestion.

DAF is a viable clarification process, especially for source waters with low turbidity (infrequent spikes up to $100 \mathrm{NTU}$ ), high algal blooms and high colour. Bench-scale DAF assisted sludge thickening resulted in performance similar to gravity thickeners. High recycle ratios (around or greater than 100 percent) were required for effective sludge thickening [6].

The main objectives of sludge digestion are a) to destroy the pathogenic organisms remaining in the thickened sludge by the effect of high temperature, b) to destroy the organic matter remaining in the thickened sludge (volatile organic content) and convert it to methane gas, c) to make the sludge more stable and easy to manage during the ultimate disposal, d) to reduce the final volume of sludge and the disposal costs, and e) to make the sludge easier for dewatering process.

Chromium has been identified as activated sludge inhibitor, or even toxicant in relatively high concentration, whereas inert or stimulant effects have been reported for relatively low concentrations. Actually quite early research works on chromium effects on sewage organisms indicated minimal effects at chromium concentration below $25 \mathrm{mg} / 1$ [7].

To assess the WWTP performance, some authors proposed indicators of sludge quality, costs or production per equivalent population [8], while Murray et al. focused on the biosolids production in dry ton/day[9]. Others considered the sludge production in the operating cost index [10] [11] or in life cycle 
approaches [12] [13].

\section{II.RESEARCH METHODS}

Gabal El-Asfar Wastewater treatment plant GAWWTP is one of the biggest wastewater treatment plant around the world located in the north of Cairo the capital of Egypt. GAWWTP is divided into three stages, each stage has a working capacity of 1 million $\mathrm{m}^{3} / \mathrm{d}$, can be exceeded by $20 \%$ at peak time Figure 1. Only stage 1 and half of stage 2 are finished and working with total capacity $1.5-1.6$ million $\mathrm{m}^{3} / \mathrm{d}$.

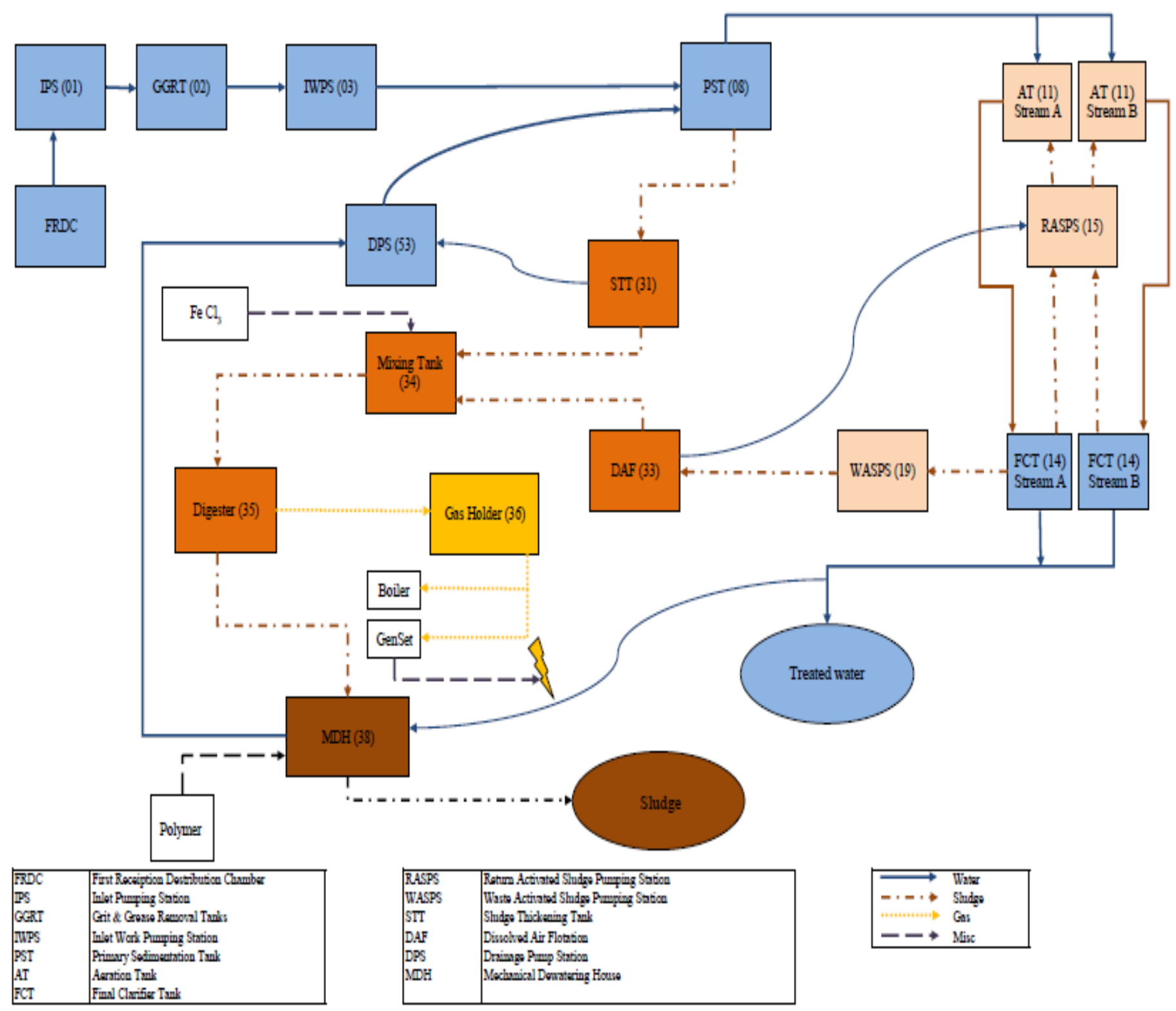

Fig.1: Flow Line of one of the three Stages of Gawwtp

To assess the performance of the wastewater treatment plant, we made a sampling plan to measure the amount of suspended solids in sludge through all the stages included in the sludge line. The time scheduled for this sampling program was six months. Also we took into our consideration to montor the chromium concentration in the sludge through the six months to check if it exceeded above the maximum Egyptian standard regulation Table.1.

The sludge sample were taken from six ports in the waste sludge line. The six sampling ports are at the 1) primary gravity thickener, 2) secondary gravity thickener, 3) Group thickeners outlet, 4) Sludge digesters inlet, and 5) Sludge digesters outlet. At the Same time according to the analysis of the previous samples, the sludge digesters efficiency and the percentages of sludge dryness during dewatering stage were determined.

We used the standard methods for the examination of water and wastewater on all the samples. The experiment on sludge were applied to determine alkalinity- titration, volatile fatty acids, volatile and dissolved solids in addition to the normal analysis of samples to identify its physical properties 
TABLE. 1

MaXimum Concertation Limits Of Heavy Metals In Sludge According To The Egyptian Regulation

\begin{tabular}{|l|c|c|c|c|c|c|c|c|}
\hline & \multicolumn{7}{c|}{ Heavy Metals } \\
\cline { 2 - 8 } & $\mathrm{Zn}$ & $\mathrm{Pb}$ & $\mathrm{Cd}$ & $\mathrm{Cu}$ & $\mathrm{Cr}$ & $\mathrm{Ni}$ & $\mathrm{Hg}$ & $\mathrm{As}$ \\
& $\mathrm{mg} / \mathrm{kg}$ & $\mathrm{mg} / \mathrm{kg}$ & $\mathrm{mg} / \mathrm{kg}$ & $\mathrm{mg} / \mathrm{kg}$ & $\mathrm{mg} / \mathrm{kg}$ & $\mathrm{mg} / \mathrm{kg}$ & $\mathrm{mg} / \mathrm{kg}$ & $\mathrm{mg} / \mathrm{kg}$ \\
\hline $\begin{array}{l}\text { Maximum } \\
\text { Egyptian } \\
\text { Regulation }\end{array}$ & 2800 & 300 & 39 & 1500 & 1200 & 420 & 17 & 41 \\
\hline
\end{tabular}

\section{RESULTS AND DISCUSSIONS}

The average concentrations of solids in sludge through different stages of the sludge line per month are shown in Table 1. The average concentration of suspended solids in the primary sludge at the inlet primary gravity thickeners were ranged between $8.1 \mathrm{gm} / \mathrm{l}$ and $9.1 \mathrm{gm} / \mathrm{l}$ with average concentration $8.5 \mathrm{gm} / \mathrm{l}$ through the whole period of assessment Figure 2. The average concentration of suspended solids in the secondary sludge at the inlet secondary gravity thickeners were ranged between $2.2 \mathrm{gm} / 1$ and $3.2 \mathrm{gm} / 1$ with average concentration $2.92 \mathrm{gm} / \mathrm{l}$ through the whole period of assessment. At the end of the sludge thickening stage, the average concentration of dissolved solids in sludge became with a range between $63 \mathrm{gm} / 1$ and $72 \mathrm{gm} / 1$ with average concentration $67.83 \mathrm{gm} / \mathrm{l}$ through the whole period of assessment.

The average monthly dissolved solids concentration at the outlet of the DAF unit were decreased to a range between 31 $\mathrm{gm} / \mathrm{l}$ and $41 \mathrm{gm} / \mathrm{l}$ with average value of $35.17 \mathrm{gm} / \mathrm{l}$ through the six months. During the mixing Sludge stage before the inlet of the sludge digesters, the solid concentration in sludge were ranged between $49 \mathrm{gm} / 1$ and $55 \mathrm{gm} / \mathrm{l}$ with an average of 50.67 $\mathrm{gm} / \mathrm{l}$.

Finally, at the end of the sludge digestion stage the average concentration of sludge were decreased to a range between 36 $\mathrm{gm} / 1$ and $38 \mathrm{gm} / 1$ with an average of $37 \mathrm{gm} / 1$ through the whole research period. Table 3 represent the average monthly digesters efficiency of minimizing the volatile dissolved solids load were ranged between $39 \%$ and $47 \%$ with an average 42.8 $\%$ of VDS load Figure 3.

The Average Concentrations Of Suspended Solids In SLudge Through DifFERENT Stages OF SLUDGE LINE PER MONTH

\begin{tabular}{|l|c|c|c|c|c|c|}
\hline & \multicolumn{7}{|c|}{ Month } \\
\cline { 2 - 8 } & $\mathbf{1}$ & $\mathbf{2}$ & $\mathbf{3}$ & $\mathbf{4}$ & $\mathbf{5}$ & $\mathbf{6}$ \\
\hline Primary thickeners (gm/l) & 8.1 & 8.9 & 7.6 & 8.4 & 9.1 & 8.9 \\
\hline $\begin{array}{l}\text { Secondary thickeners } \\
\text { (gm/l) }\end{array}$ & 3.1 & 3.2 & 2.7 & 2.2 & 3.3 & 3.0 \\
\hline Thickeners Outlet (gm/l) & 72 & 69 & 65 & 63 & 70 & 68 \\
\hline DAF outlet (gm/l) & 41 & 34 & 31 & 31 & 38 & 36 \\
\hline $\begin{array}{l}\text { Mixed Sludge (Digester } \\
\text { Inlet) (gm/l) }\end{array}$ & 55 & 53 & 49 & 49 & 50 & 48 \\
\hline Digesters Outlet (gm/l) & 37 & 37 & 36 & 36 & 38 & 38 \\
\hline
\end{tabular}




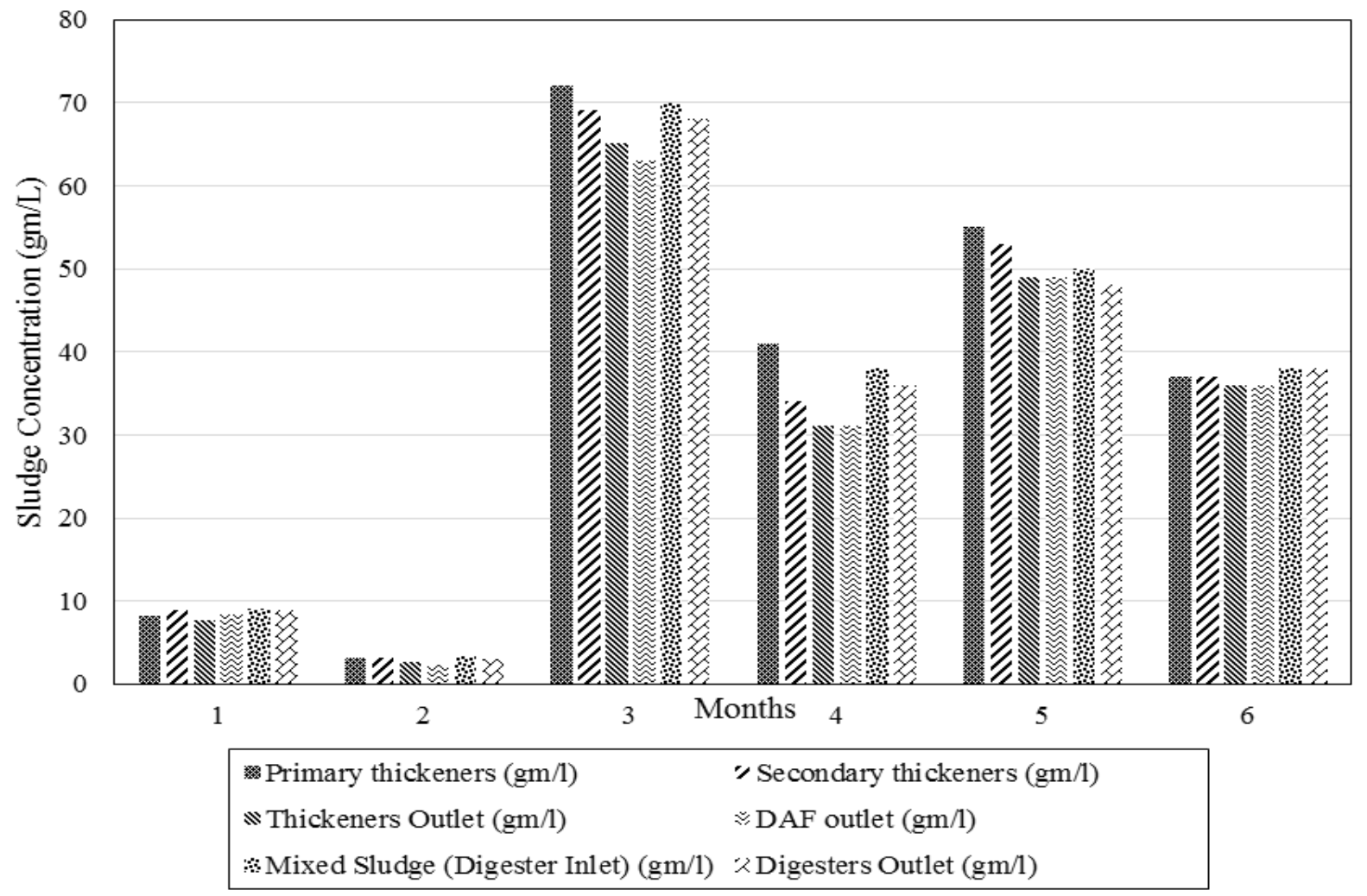

Fig. 2:Average Sludge Concentrations Per Month Through Different Stages of the Sludge Line



Fig. 3: Average Sludge Digesters Efficiency Per Month

Dewatering Stage is a continuing stage in sludge treatment process. The average monthly amount of TDS/d were ranged from $90 \mathrm{t} / \mathrm{d}$ to $135 \mathrm{t} / \mathrm{d}$ with an average value of $120 \mathrm{t} / \mathrm{d}$ Figure 4. About the percentage of Dryness, it ranged between $23 \%$ and $25 \%$ with average value of $24 \%$. 

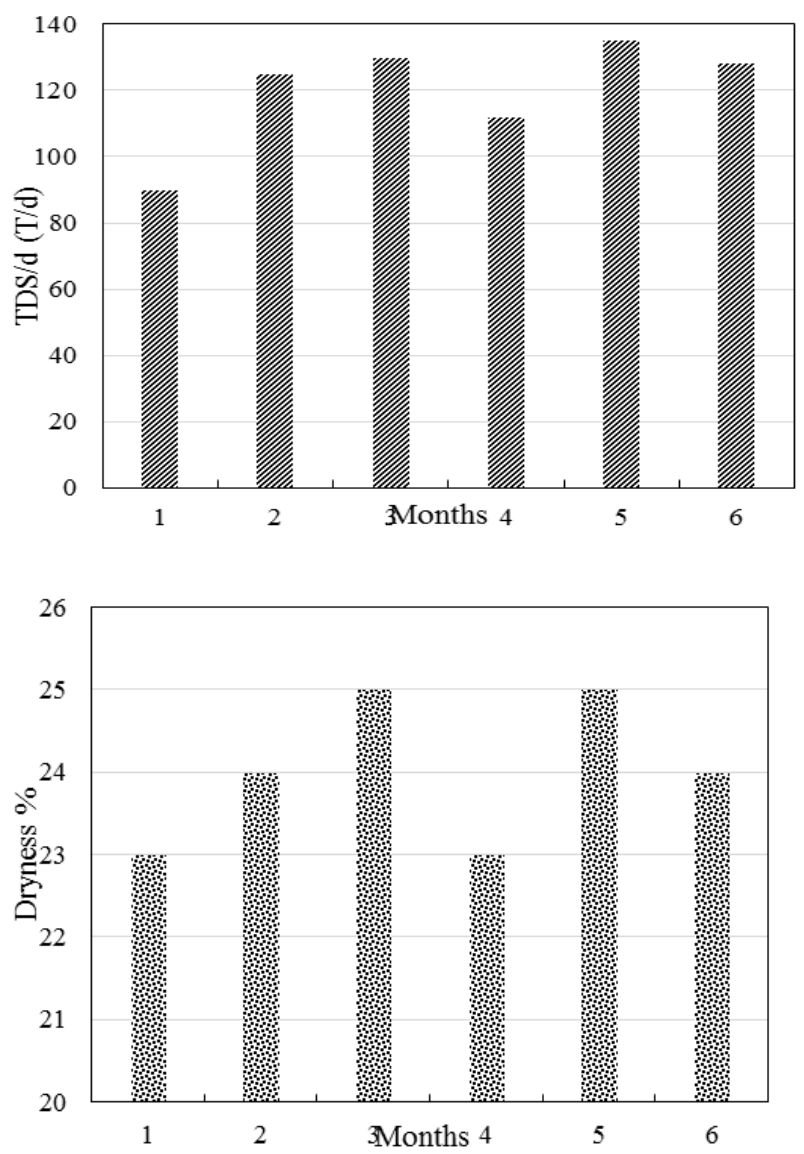

Fig. 4: Sludge Dewatering Stage Results

According to the monitoring plan of one the important heavy metals, we found the average monthly concentration of chromium Cr in sludge ranged between $1049 \mathrm{mg} / \mathrm{kg}$ and 1168 $\mathrm{mg} / \mathrm{kg}$ with average concentration $1116.3 \mathrm{mg} / \mathrm{kg}$ Figure 5 .

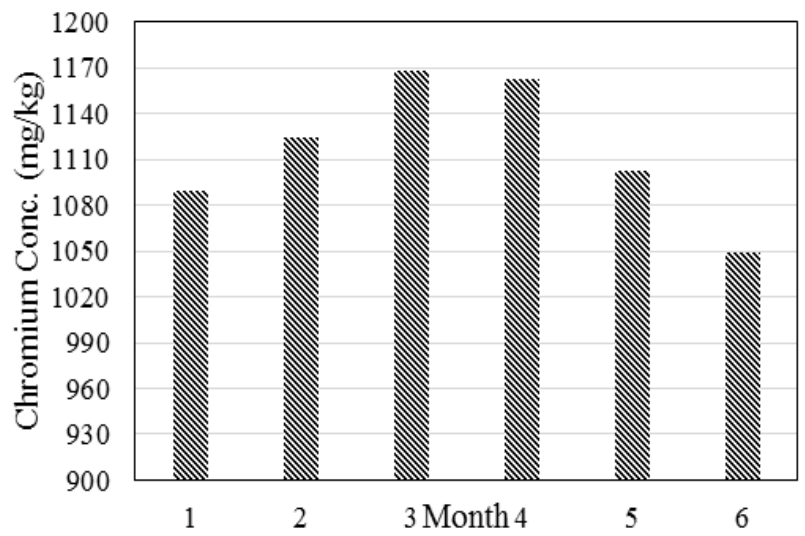

Fig. 5: Chromium Cr Concentrations In Sludge

\section{CONCLUSION}

Our study put a significant basis for the assessing process of the performance of the sludge line in a huge wastewater treatment plant including all the stages needed for sludge treatment. Results of this research illustrates the variation in the concentration of solids in sludge over a period of six months in six different sampling ports through the sludge line of GAWWTP. The concentration of solids in sludge is respectively high but still below the critical limit of the wastewater treatment plant. So we recommended that the sludge treatment line need an improvement process before the beginning of the next future extension works (the remaining part of stage 2 and stage 3 ). The second task of our research was to make a monitoring plan to check that the concentration of one of the most dangerous heavy metals in sludge which is chromium Cr. Our conclusion was that the average monthly concentration of chromium is less than the maximum acceptable level according to the Egyptian law, although we found some increase in chromium concertation during some few days. Finally, we recommended to add this research plan and objectives to be a part of the periodic monitoring process for GAWWTP.

\section{REFERENCES}

[1] Mahdi Ghafarzadeh, Rezvan Abedini, and Rohollah Rajabi, "Optimization of ultrasonic waves application in municipal wastewater sludge treatment using response surface method", Journal of Cleaner Production, Volume 150, 1 May 2017, Pages 361-370. https://doi.org/10.1016/j.jclepro.2017.02.159

[2] Qilin Wang, Wei Wei, Yanyan Gong, Qiming Yu, Qin Li, Jing Sun, Zhiguo Yuan, "Technologies for reducing sludge production in wastewater treatment plants: State of the art", Science of The Total Environment, Volumes 587-588, June 2017, Pages 510-521. https://doi.org/10.1016/j.scitotenv.2017.02.203

[3] Ville Turunen, Jaana Sorvari, Anna Mikola, "A decision support tool for selecting the optimal sewage sludge treatment", Chemosphere, Volume 193, February 2018, Pages 521-529. https://doi.org/10.1016/j.chemosphere.2017.11.052

[4] A. Kelessidis, A.S. Stasinakis, "Comparative study of the methods used for treatment and final disposal of sewage sludge in European countries", Waste Manage, 32 (2012), pp. 1186-1195. https://doi.org/10.1016/j.wasman.2012.01.012

[5] L. Appels, J. Baeyens, J. Degreve, R. Dewil, "Principles and potential of the anaerobic digestion of waste-activated sludge", Prog. Energy Combust. Sci., 34 (6) (2008), pp. 755-781. https://doi.org/10.1016/j.pecs.2008.06.002

[6] Harish Arora, James R. De Wolfe, Ramon G. Lee, Thomas P. Grubb, "Evaluation of dissolved air flotation process for water clarification and sludge thickening", Technology, Volume, 1995, Pages 137-147

[7] Eleni Vaiopoulou, Petros Gikas, "Effects of chromium on activated sludge and on the performance of wastewater treatment plants", Water Research, Issue 46, 2012, Pages 549-570. https://doi.org/10.1016/j.watres.2011.11.024

[8] P. Balmer, D. Hellström, "Performance indicators for wastewater treatment plants", Water Science Technology., 65 (7) (2012), pp. 13041310. https://doi.org/10.2166/wst.2012.014

[9] A. Murray, I. Ray, K.L. Nelson, “An innovative sustainability assessment for urban wastewater infrastructure and its application in Chengdu", China, Journal of Environmental Management., 90 (2009), pp. 3553-3560. https://doi.org/10.1016/j.jenvman.2009.06.009

[10] A. Gallego, A. Hospido, M.T. Moreira, G. Feijoo, "Environmental performance of wastewater treatment plants for small populations", Resources. Conservation. Recycling., 52 (2008), pp. 931-940 https://doi.org/10.1016/j.resconrec.2008.02.001.

[11] H.R. Concepción, M. Meneses, R. Vilanova, "Control strategies and wastewater treatment plants: effect of controller's parameters variation", 16th International Conference on Engineering Technologies and Factory Automation, Toulouse, France, 5-9 September (2011). https://doi.org/10.1109/ETFA.2011.6059057 
[12] P.P. Kalbar, S. Karmakar, S.R. Asolekar, “Assessment of wastewater treatment technologies: life cycle approach", Water Environment Journal, 27 (2013), pp. 261-268.

https://doi.org/10.1111/wej.12006

[13] C. Silvaa, J. Saldanha Matosb, M. J. Rosaa, "Performance indicators and indices of sludge management in urban wastewater treatment plants", Journal of Environmental Management, volume 184, Part 2, 15 December 2016, Pages 307-317.

https://doi.org/10.1016/j.jenvman.2016.09.056 